\title{
Evaluation of Leiurus quinquestriatus scorpion venom anticancer potential against Prostate Cancer Cell Lines (PC3)
}

\author{
Tito N. Habib*,Hemely A. Hassan, Fayza M. Ali, Nadia S. Mahrous \\ *Molecular Genetics' Lab, Zoology Dept., Faculty of science, Sohag University \\ Cytogenetic Lab, Zoology Dept., Faculty of Science, (Qena) South Valley University, Egypt
}

Rec. 11 Feb, 2019 Accept. 13 Mar, 2019

\begin{abstract}
Several recent studies by others have demonstrated the preventive and therapeutic efficacy of scorpion venom in different animal tumor models and cell culture systems including prostate, breast, colon and skin cancers. Polypeptide extracted from the Egyptian scorpion venom (Leiurus quinquestriatus), is being studied for both prevention and treatment of prostate cancer. We proposed that there are alterations in pattern of cell cycle in prostate cancer cell line (PC3) post incubation with scorpion venom $(1 \mathrm{mg} / \mathrm{ml})$ for $24 \mathrm{~h}$ in vitro. The results are supported by comparing the percentage of cells in each phase of cell cycle It showed an increasing of apoptotic rate as $26.33 \%$ for pre $\mathrm{G} 1 ; 71.2 \%$ for $\mathrm{G} 1 / \mathrm{G} 0 ; 20.4 \%$ for $\mathrm{S}$, and $8.4 \%$ for $\mathrm{G} 2 / \mathrm{M}$ phases, compared with cell control recording $66.4 \%$ for G1/G0, 25.9\% for S, and $7.7 \% \mathrm{G} 2 / \mathrm{M}$ phases, respectively. Data recorded that scorpion venom induced Pre-G1 phase PC3 cell arrest for enhancing and providing the chance for the role DNA repair system. The present results providing strong rationale for further studies, to evaluate prevention and intervention strategies for $L$. quinquestriatus venom in pre-clinical prostate cancer models.
\end{abstract}

Keywords: Prostate cancer, L. quinquestriatus, DNA content, PC3, cell cycle, apoptosis.

\section{Introduction:}

An increasing number of experimental and preclinical investigations have demonstrated that crude scorpion venom and some purified proteins and peptides can impair multiple hallmarks of cancer in vitro and in vivo animal model. Myocarditis is not well documented in literature as an important cause of death in scorpion stings. Only Poon-King (1963) made a definitive point in 39 cases out of 45 patients, that the toxic myocarditis was the important cause of death.

Venom from the Egyptian scorpions Androctonus amoreuxi and Androctonus crassicauda (Buthidae) exhibited cytotoxic/antitumor properties in experimental tumor models. A. amoreuxi venom was tested in female albino mice $(0.22 \mathrm{mg} / \mathrm{kg}$, intraperitoneal administration, daily, for 14 and 30 days) in murine Ehrlich ascites and solid tumors and in cultured human breast cancer (MCF-7) cells (Zargan, et al. 2011; Salem, et al. 2016).

Some scorpion venoms target caspases, mitochondria, Bcl-2, and BAX and may thereby contribute to cancer treatment. BmKn2 peptide $(29 \mu \mathrm{g} / \mathrm{ml})$ from $\mathrm{BmK}$ venom killed cultured human oral squamous carcinoma (HSC-4) cells through the induction of apoptosis, as reflected by increased activated caspase-3, -7 and -9 mRNA levels (Tongngam, et al. 2015). A. crassicauda scorpion venom suppressed cell growth by inducing cell cycle arrest in the S-phase and cell death as a result of mitochondrial membrane depolarization (Salem, et al. 2016).

Bengalin induced apoptosis in both U937 and K562 cell lines (IC50 values of 3.7 and $4.1 \mu \mathrm{g} / \mathrm{ml}$, respectively), as confirmed by damaged nuclei, a sub G1 peak, and DNA fragmentation. Bengalin activates a mitochondrial death cascade, causing the loss of mitochondrial membrane potential and

\footnotetext{
* Corresponding author:

Dr. Nadia S. Mahrous
}

$凶$ samirnadia89@gmail.com 
activating caspase-3 and -9 (Gupta, et al. 2010).

The anti-tumor mechanism of $T$. discrepans and neopladines may be via FASL. FASL expression accompanies tumor cell death; the activation of FAS signaling by the induction of FASL constitutes the trigger mechanisms of extrinsic apoptosis (Reshkin, et al. 2003). Similarly, Odontobuthus doriae (Buthidae) (yellow Iranian scorpion) venom inhibits cell growth, induces apoptosis (increased caspase3 activity) and DNA fragmentation in cultured human neuroblastoma (SH-SYSY) and human breast (MCF-7) cancer cells (Zargan, et al. 2011). The scorpion venom induced chromatin condensation, increased P53 and Bax mRNA, activated caspases- $3,-8$, and -9 , and decreased Bcl-2 transcript levels. There was no effect on either normal or hematopoietic tumor cells. It is known that the tumor suppressor protein p53 accumulates when DNA is damaged, interrupting the cell cycle at G1 for repair (Knudson, 1986). The loss of p53 is associated with resistance of cancer cells to apoptosis, contributing to the formation of tumors. The p53 tumor suppressor protein is lost due to homologous loss in $70 \%$ of colon cancers, 30 $50 \%$ of breast cancers, and 50\% of lung cancers (Attardi \& Jacks 1999). Mutations in p53 or PTEN are among the most frequent causal events in many cancers, and their combined inactivation has profound consequences in terms of promoting tumor development. Several scorpion venoms can beneficially modulate PTEN and/or p53 and are hence promising multi-targeting therapeutic agents. Chlorotoxin (CTX) is a 36amino acid peptide derived from the Egyptian scorpion Leiurus quinquestriatus (Buthidae), which inhibits low-conductance $\mathrm{Cl}$ channels (DeBin and Maggio 1993). The interaction between cells and components of the extracellular matrix plays a fundamental role in tumor cell invasion. Proteolysis of the extracellular matrix by matrix metalloproteinases (MMPs) facilitates this process (Tatti \& Gucciardo et al. 2015). Prostate cancer (PC) is the most common and the second most fatal cancer among men in the industrialized world (Zhu, et al. 2006). PC is a multifocal, non-clonal and heterogeneous tumor that most commonly originates in the peripheral zone of the prostate (Bostwick, 1989). However, it is hypothesized that PC arises from the age-associated accumulation ofgenetic/epigenetic changes (e.g., aneuploidy, loss of heterozygosity, mutations, inactivation of tumor suppressors and activation of protooncogenes) in prostatestem/precursor cells, their associated factors or in the stem cell niche (Wei, et al. 2007; Prajapati, et al. 2013). PC3 is one of the cell lines used in prostate cancer research. These cells are useful in investigating the biochemical changes in advanced prostatic cancer cells and in assessing their response to chemotherapeutic agents. Moreover, they can be used to create subcutaneous tumors in mice in order to investigate a model of the tumor environment in the context of the organism. The PC3 cell line was established in 1979 from bone metastasis of grade IV of prostate cancer in a 62-year-old Caucasian male (Kaighn, et al. 2012). In general, the progression of cell cycle in eukaryotes is a complex process involving arresting G0 phase, and cell growth involving G1, S and G2/M phases in a step-wise manner (Agarwal, 2000). Apoptosis is regulated by different protein families, including the upstream Bcl-2 family, the anti-apoptotic (Bcl$2)$ and pro-apoptotic (Bax) and the downstream caspase family (caspase3). Molecules such as B-cell lymphoma leukaemia-2 (Bcl-2)/Bax system play a critical role in the regulation of the apoptotic process. $\mathrm{Bcl}-2$ is an intracellular protein that inhibits apoptosis, while Bax counteracts the antiapoptotic function of Bcl-2 by binding to this molecule (Oltvai, et al. 1993). The development of new flowcytometric application will facilitate the research in prostate carcinogenesis. A better understanding of the biology of prostate cancer will bring more effective ways in prevention, early diagnosis, and treatment of prostate cancer. Our attempts have been made to study of the antitumor effects of most toxic Egyptian scorpion L. quinquestriatus venom peptides on PC in vitro by using the cell cycle by flow cytometry technique. 


\section{Materials \& Methods: Cell culture}

Prostate (PC-3) cancer and Vero were propagated in $75 \mathrm{~cm} 2$ cell culture flasks (TPPSwiss) using RPMI1640/E-199 medium (Gibco-USA) supplemented with $10 \%$ (v/v) fetal bovine serum (Gibco-USA) and incubated in $5 \%(\mathrm{v} / \mathrm{v}) \mathrm{CO} 2$ incubator at a temperature of $37^{\circ} \mathrm{C}$. Confluent cells were detached using $0.25 \%(\mathrm{w} / \mathrm{v})$ trypsin solution and $0.05 \%(\mathrm{v} / \mathrm{v})$ ethylene diaminetetraacetic acid (Gibco-USA) for $5 \mathrm{~min}$. Cells were plated at a concentration of $2 \times 105$ cells $/ \mathrm{ml}$ in 96well cell culture plates and incubated at a temperature of $37^{\circ} \mathrm{C}$ for 24 hours to achieve confluence.

Leiurus quinquestriatus venom was extracted by mild electrical stimulation $(20 \mathrm{~V}$, $500 \mathrm{~mA}$ ) and diluted in sterile double-distilled water. After centrifugation at $8,000 \mathrm{~g}$ for 15 min at a temperature of $4{ }^{\circ} \mathrm{C}$ (Jouan KI 22, France), the supernatant was immediately lyophilized and stored at a temperature of $20^{\circ} \mathrm{C}$ until used (Borges, et al., 2006) Leiurus quinquestriatus scorpion venom was reconstituted in serum and phenol red-free medium. Cytotoxicity (MTT Assay) of venom to test cell lines (PC3/ Vero) was performed as the medium was decanted and fresh medium containing various concentrations of venom was added for cytotoxicity determination using colorimetric MTT reduction assay. (Mosmann, 1983) Morphological alterations of cells were analyzed using an inverted microscope (Nikon-Japan). Dead cells were washed out using phosphate-buffered-saline (PBS) and 50 1 of MTT stock solution $(5 \mathrm{mg} / \mathrm{ml})$ were added to each well. After $4 \mathrm{~h}$ incubation period, the supernatants were discarded and the formazan precipitates were solubilized by addition of 501 per well of (DMSO) dimethyl sulfoxide or $0.4 \%(\mathrm{v} / \mathrm{v})$ acidified isopropanol (Sigma- Aldrich-USA). Plates were incubated in the dark for $30 \mathrm{~min}$ at a temperature of $37^{\circ} \mathrm{C}$ and absorbance was determined at a wavelength of $570 \mathrm{~nm}$ using micro plate reader (Biotek ELX -800, USA). The cell viability percentage was calculated using the following formula:

Cell viability $(\%)=\mathrm{OD}$ of treated wells/ OD of cell cont x 100
The cell viability (\%) was blotted against the tested venom concentrations.

Cell Cycle Analysis of PC-3 / Vero cells treated with the $\mathrm{IC}_{\mathbf{5 0}}$ of test venom dissolved in RPMI-1640 medium, for $24 \mathrm{~h}$. For cell cycle analysis, the cells were harvested and fixed gently with $70 \%(\mathrm{v} / \mathrm{v})$ ethanol in PBS, maintained at a temperature of $4^{\circ} \mathrm{C}$ overnight and then re-suspended in PBS containing 40 $\mu \mathrm{g} / \mathrm{ml} \mathrm{PI}$ and $0.1 \mathrm{mg} / \mathrm{ml}$ RNase and $0.1 \%(\mathrm{v} / \mathrm{v})$ Triton X100 in a dark room. After $30 \mathrm{~min}$ at $37^{\circ} \mathrm{C}$, the cells were analyzed using a flowcytometer (Becton-Dickinson, San Jose, CA, USA) equipped with an argon ion laser at a wavelength of $488 \mathrm{~nm}$. The cell cycle and subG1 group were determined and analyzed, as described previously. (Kuo, et al., 2007)

\section{Statistical analysis:}

Significance between treated and untreated cells was determined using one way ANOVA. Differences at $\mathrm{P}$ values less than 0.05 were considered significant. The IC50 values of test venoms were determined using Masterplex2010 software program.

\section{Results:}

The induced cell toxicity was accompanied with morphological changes in the culture fields showing a polygonal shape with distinct boundaries and homogenous cellular contents. On the other hand, a number of morphological abnormalities of cells were observed $24 \mathrm{~h}$ post treatment with Leiurus venom. At the lowest concentrations, cells lost their characteristic appearance, became rounded and detached out of the culture surface, while other cells retained their normal morphological appearance. Increasing venom concentrations resulted in increased cellular irregularities and larger areas devoid of cells. At the highest concentrations, cells showed obvious deterioration and deformation with severe shrinkage and condensation of their cellular contents., The viability $\%$ of treated cells was concentration-dependent and the $\mathrm{IC}_{\mathbf{5 0}}$ values were Significantly low $(\mathrm{P}<0.05)$ than in case of Vero cells; 32 and $81 \mu \mathrm{g} / \mathrm{ml}$ respectively [Fig. 1-2]. 


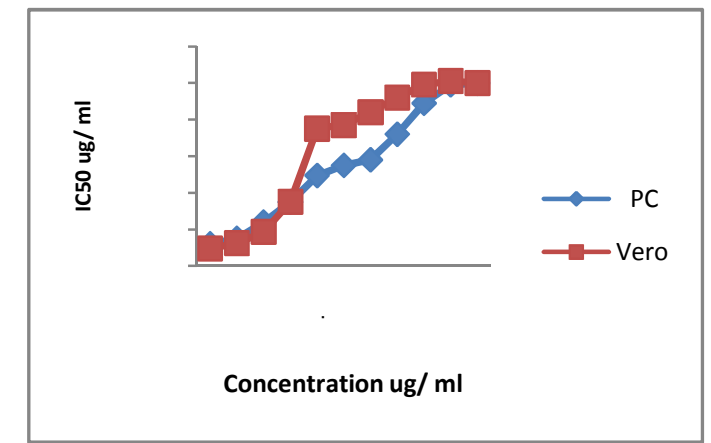

[Fig.1]: Evaluation of cell viability of PC3 and Vero cells using MTT assay.

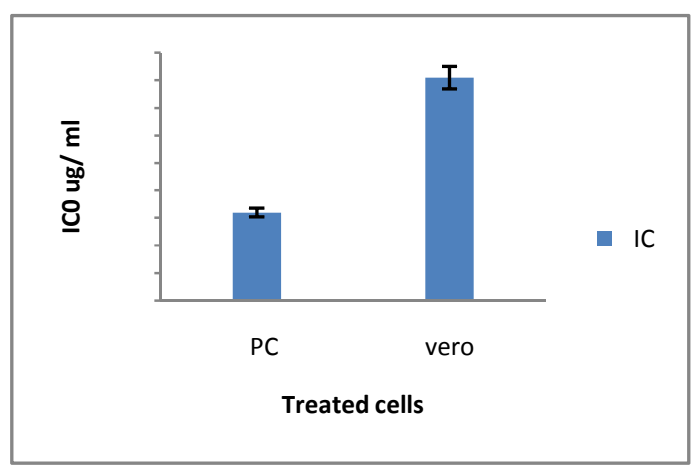

[Fig.2] Evaluation of inhibitory concentration of Leiurus venom using Masterplex 2010

Soft ware

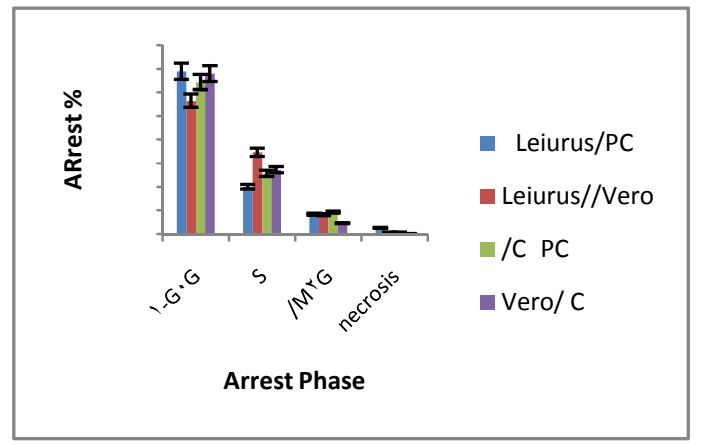

[Fig.3] Cell Cycle Analysis Toxicity of Leiurus venom was accompanied by cell cycle arrest in both PC-3 and Vero cell lines.

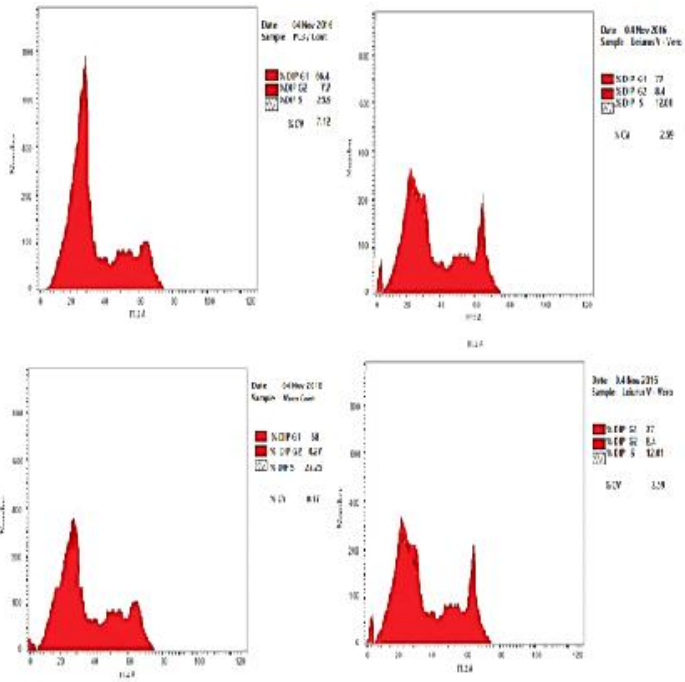

[Fig.4]: Evaluation of cell cuycle profile post PC3 and Vero cells using Leiurus venom compared with untreated cell controls using flow cytometry.

Data recorded revealed that Leiurus venom showed a significant $(\mathrm{P}<0.05)$ accumulation of DNA through the G0-G1 phase of cell cycle. In the mean time there was an insignificant arrest during the $\mathrm{S}$ and $\mathrm{G} 2 / \mathrm{M}$ phases $(\mathrm{P}>0.05)$ compared with arrest \% in untreated cell control. In the same time Vero cells showed a significant $(\mathrm{P}<0.05)$ arrest through the $\mathrm{G} 2 / \mathrm{M}$ phase, oppositely incase of the PC3 cell line there was insignificant \% (P>0.05) of arrest [Fig.3]. Concurrently there was insignificant arrest \% of cells during the $\mathrm{S}$ and G0-G1 phases in case of Vero cells treated [Fig.4].

\section{Discussion:}

The anti-proliferative effect of honey on human (A375) and murine (B16-F1) melanoma cell lines was found to be mediated by G0/G1 cell cycle arrest and induction of hyperploid progression (Swellam, et al. 2003; Pichichero, et al. 2010). DNA content was determined by flow cytometry of PI-stained cells. There were an increased proportion of cells in G2-M when compared with nontreated controls for all cell lines. An increase in the percentage of total cells in the sub- $\mathrm{G}_{0^{-}}$ $\mathrm{G}_{1}$ peak, characteristic of apoptotic cells, was observed progressively over 24-h and 48-h exposure periods. PC-3 cells were less responsive to cryptophycin 52 than $\mathrm{LNCaP}$ 
and DU-145 cells with respect to $\mathrm{G}_{2}-\mathrm{M}$ arrest over the same time frame (Drew, et al. 2002).

HP8, a formula of Australian and European herbs and other natural ingredients, has been evaluated in in vitro for its anti-proliferative effects against androgen independent prostate cancer cell line PC-3 and the androgen dependent prostate cancer cell line LNCap cultured by standard in vitro techniques. Its biological activity against these cell lines was compared to its activity against non-prostate cancer cell lines, HepG2 (liver cancer), and HL60 (human leukaemia). Inhibition of the in vitro proliferation PC-3 and LNCap cell lines occurred in a dose dependent manner. Analysis by flow cytometry determined that cell division was arrested at the G2/M phase of the mitosis cycle resulting in apoptosis within 24 hours. Significantly lower rates of G2/M arrest and apoptosis in the non-prostate cancer cell lines demonstrated that HP8's inhibitory effects were selective toward prostate cancer cell lines.

The effects of Moringa oleifera flower extract anticancer properties were studied by cell cycle analysis. The distribution of cell cycle phases was expressed in histograms of PC-3 cells after exposed with $25 \mathrm{~g} / \mathrm{ml}$ of $M$. oleifera flower extract are in untreated, growing PC-3 cells, the $G_{0} / G_{1}$ phases were clearly well defined with many demarcating cells. After $24 \mathrm{~h}$ of $12.5 \mathrm{~g} / \mathrm{ml} \quad M$. oleifera flower extract treatment, the percentage of cells in the G0/G1 phase significantly decreased from $93.1 \%$ to $57.7 \%$ compared to control. The cells treated for $48 \mathrm{~h}$, a notable decrease in G0/G1 phase was observed indicating $M$. oleifera flower extract on PC-3 cell cycle arrest appears to be timeindependent manner; the higher the treatment time, the lower the percentage of the cells in the G0/G1 phase. It is suggested that the MO flower extract could induced cell cycle arrest in the higher treatment time (Ju, et al. 2018).

Huang, et al. (2017) showed that papaverine selective antitumor properties against PC-3 human prostate cancer cells by inducing early and late apoptosis, sub-G1 cell cycle arrest, modulation of apoptosis-related proteins like Bcl-2, Bax, Bid, XIAP and cytochrome $\mathrm{C}$ along with down regulation of NFkB, PI3K/Akt signaling pathway.

Moreover, Son et al. (2007) showed that caspase-3 was most potently activated by SVT, and this activation was attenuated in cells transected with mutant p50, IKKa, and IKKh. These data suggest that the activation of caspase-3 is critical in SVT-induced PC-3 cell death. The cell cycle analysis data showed that SVT caused a strong G0-G1 cell cycle arrest and a weak G2-M arrest in prostate cancer cells. Furthermore, mechanistic investigation showed that SVT-induced G0-G1and G2-M phase arrest in PC-3 cells and this result.

In the present study, changes of the arrested cell cycle phases in PC 3 using flow cytometry after $24 \mathrm{~h}$ of post scorpion venom treatment were $26.33 \%$ for pre $\mathrm{G} 1 ; 71.2 \%$ for $\mathrm{G} 1 / \mathrm{G} 0$; $20.4 \%$ for $\mathrm{S}$, and $8.4 \%$ for $\mathrm{G} 2 / \mathrm{M}$ phases, In the meantime, the control cells showed $66.4 \%$ for $\mathrm{G} 1 / \mathrm{G} 0,25.9 \%$ for $\mathrm{S}$, and $7.7 \% \mathrm{G} 2 / \mathrm{M}$ phases, correspondingly. Thus, it indicates that the scorpion venom pushed PC3 cells in the direction of cell arresting phase (Pre G1) for enhancing and providing the chance for the role DNA repair system.

The results of the study suggest that scorpion venom prevented prostatic hyperplasia significantly in a dose-dependent manner with showing the best activity and assumes significance in view of the fact that scorpion venom stops the synthesis of DNA in cancerous cells.

\section{References:}

Agarwal, R. (2000). Cell signaling and regulators of cell cycle as molecular targets for prostate cancer prevention by dietary agents. Biochem.Pharmacol.,60(8):10 51-1059.

Attardi, L. and Jacks, T. (1999). The role of p53 in tumor suppression: lessons from mouse models. Cell Mol. Life Sci., 55 (1): 48-63.

Borges, A., Garcia, C.C., Lugo, E., Alfonzo, M.J., Jowers, M.J. (2006). Diversity of long-chain toxins in Tityuszulianus and Tityusdiscrepans venoms (Scorpiones, Buthidae): molecular, immunological and mass spectral analyses. Comparative Biochemistry 
and Physiology Part C: Toxicology and Pharmacology, 142(3):240- 252.

Bradford, M.M. (1976). A rapid and sensitive method for the quantitation of microgram quantities of protein utilizing the principle of protein-dye binding. Analytical Biochemistry, 72(1-2):248-254.

Bostwick, D.G. (1989). The pathology of early prostate cancer. CA Cancer J. Clin., 39:376393.

Drew, L., Fine, R., Do, T.N., Douglas, G.P. and Petrylak, D.P. (2002). The Novel Antimicrotubule Agent Cryptophycin 52 (LY355703) Induces Apoptosis via Multiple Pathways in Human Prostate Cancer Cell.Clin. Cancer Res.,8(12):3922-3932.

DeBin, J. and Maggio, J. (1993). Purification and characterization of chlorotoxin, a chloride channel ligand from the venom of the scorpion. Am. J. Physiol., 264 (Pt1): 361-369.

Gupta, S. and Gomes, A. (2010). Apoptosis induction in human leukemic cells by a novel protein Bengalin, isolated from Indian black scorpion venom: through mitochondrial pathway and inhibition of heat shock proteins." Chem. Biol. Interact., 183 (2): 293303.

Huang, H., Li, L.J., Zhang, H.B., and Wei, A.Y. (2017). Papaverine selectively inhibits human prostate cancer cell (PC-3) growth by inducing mitochondrial mediated apoptosis, cell cycle arrest and downregulation of $\mathrm{NF}-\kappa \mathrm{B} / \mathrm{PI} 3 \mathrm{~K} / \mathrm{Akt}$ signaling pathway. JBUON, 22(1): 112-118.

Ju, J., Gothai, S., Hasanpourghadi, M., Nasser, A.A., Ibrahim, A.I., Shahzad, N. and Pandurangan, A.K. (2018). Anticancer potential of Moringa oleifera flower extract in human prostate cancer $\mathrm{PC}-3$ cells via induction of apoptosis and downregulation of AKT pathway. (14)58; 477-481.

Kaighn, M.E., Shankar Narayan, K., Ohnuki, Y., and Jones, L.W. (2012).
Establishment of a human prostate cancer cell line (PC-3). Investigative urology, 17(1):16-23.

Kuo, L.E., Kitlinska, J.B., Tilan, J.U., Baker, S.B., Johnson M.D. (2007): Nat. Med; 13:803-11.

Mosmann, T. (1983). Rapid colorimetric assay for cellular growth and survival: application to proliferation and cytotoxicity assays. Journal of lmmunological Methods, 65(1-2):5563.

Oltvai, Z.N., Milliman, C.L. and Korsmeyer, S.J. (1983). Bcl-2 heterodimerizes in vivo with a conserved homolog, Bax, that accelerates programmed cell death. Cell 74:609-19. 22. Yang E, Korsmeyer SJ. Molecular apoptosis: a discourse on the Bcl2 family and cell death. Blood, (1996);88:386-401.

Pichichero, E., Cicconi, R., Mattei, M., Muzi, M.G., and Canini, A. (2010). Acacia honey and chrysin reduce proliferation of melanoma cells through alterations in cell cycle progression. Int. J. Oncol., 37: 973-981.

Prajapati, A., Gupta, S., Mistry, B., and Gupta, S. (2013). Prostate stem cells in the development of benign prostate hyperplasia and prostate cancer: emerging role and concepts. Bio. Med. research international, (2013):107154.

Poon-king, T. (1963). Myocarditis from scorpion stings. Brit. Med. Jr., 1, 374.

Rabia, Y., Hafiz, M.T., Muhammad, A., Sajida, N. and Muhammad, M.A. (2016). Optimization of the Conditions for Maximum Recovery of Venom from Scorpions by Electrical Stimulation. Pakistan J. Zool., 48(1);265-269.

Reshkin, S. and Bellizzi, A. (2003): "Paclitaxel induces apoptosis via protein kinase A- and p38 mitogenactivated protein dependent inhibition of the $\mathrm{Na}+\mathrm{H}+$ exchanger (NHE) NHE isoform 1 in human breast cancer cells." Clin. Cancer Res., 9(6): 23662373. 
Salem, M.L., Shoukry, N.M., Teleb, W.K., Abdel-Daim, M.M. and AbdelRahman, M.A. (2016): In vitro and in vivo antitumor effects of the Egyptian scorpion Androctonus amoreuxi venom in an Ehrlich ascites tumor model. Springer Plus 5: 570.

Son, D.J., Park, H.M. and Chae, S.J. (2007). Inhibitory effect of snake venom toxin from Vipera lebetina turanica on hormone-refractory human prostate cancer cell growth: induction of apoptosis through inactivation of nuclear factor kappa B. Mol. Cancer Ther., 6(2):675-683.

Swellam, T., Miyanaga, N., Onozawa, M., Hattori, K., and Kawai, K. (2003). Antineoplastic activity of honey in an experimental bladder cancer implantation model: in vivo and in vitro studies. Int J Urol 10: 213-219.

Tatti, O., Gucciardo, E., Pekkonen,

P., Holopainen, T., Louhimo, R., Repo, P., Maliniemi, P., Lohi, J., Rantanen, V., Hautaniemi, S., Alitalo, K., Ranki, A., Ojala, P.M., Keski-Oja, J. and Lehti, K.
(2015). MMP16 Mediates a Proteolytic Switch to Promote CellCell Adhesion, Collagen Alignment, and Lymphatic Invasion in Melanoma. Cancer Res., 15;75(10):2083-2094.

Tong-ngam, P., Roytrakul, S. and Sritanaudomchai, H. (2015). BmKn-2 scorpion venom peptide for killing oral cancer cells by apoptosis. Asian Pac. J, Cancer Prev., 16: 2807-2811.

Wei, C., Guomin, W., Yujun, L. and Ruizhe, Q. (2007). Cancer stem-like cells in human prostate carcinoma cells DU145: the seeds of the cell line? Cancer Biol. Ther., 6:763-768.

Zargan, J., Sajad, M. Naime, M., Ali, S. and Khan, H.A. (2011). "Scorpion (Androctonus crassicauda) venom limits growth of transformed cells (SHSY5Y and MCF-7) by cytotoxicity and cell cycle arrest." Exp. Mol. Pathol., 91(1): 447-454.

Zhu, Y., Zheng, T., Stevens, R.G., Zhang, Y. and Boyle, P. (2006). Does clock" matter in prostate cancer? Cancer Epidemiol. Biomarkers Prev., 15(1):3-5 